Ciência e Natura, Santa Maria, v. 37 n. 3 set-dez. 2015, p. 833-848

Revista do Centro de Ciências Naturais e Exatas - UFSM

ISSN impressa: 0100-8307 ISSN on-line: 2179-46017218

\title{
ciênciaenatura
}

\section{A capacidade de resolver problemas: um estudo-piloto sobre a adequação de um teste de desempenho na resolução de problemas}

The ability to solve problems: a pilot study on the suitability of a performance test in solving problems

Raquel Ruppenthal, Cadidja Coutinho, Kátia Maldaner Orth, Míriam dos Santos Meira, Maria Rosa Chitolina Schetinger

\section{Resumo}

Neste trabalho, realiza-se uma revisão sobre as habilidades necessárias para a resolução de problemas, bem como de testes que permitem avaliar a capacidade de resolução de situações-problema. Com objetivo de avaliar a possibilidade de utilizar tais testes com estudantes brasileiros, aplicou-se um teste adaptado de García García \& Renteria Rodriguez (2012) com estudantes do $8^{\circ}$ e $9^{\circ}$ ano do Ensino Fundamental, de uma escola pública de Ibirubá- RS. A partir desse teste-piloto constatou-se que a maioria dos estudantes apresenta baixa capacidade para resolver problemas, sendo que os mesmos apresentam dificuldades em fatores como Predição e transferência, Capacidade de síntese e de Análise, principalmente. Observou-se que o teste necessita o acréscimo de um glossário nas questões que apresentam palavras mais complexas, a fim de que possa ser utilizado novamente.

Palavras-chave: Ensino de ciências, resolução de problemas, habilidades, testes.

\begin{abstract}
In this work, carried a review of the skills needed for solving problem, as well as tests for evaluating the capability of solve problemsituations. In order to evaluate the possibility of using such tests with Brazilian students, we applied an adapted test from García García \& Renteria Rodriguez (2012) with students of the 8th and 9th grades of elementary school, a public school Ibirubá-RS. From this pilot test it was found that most of the students has a low capacity to solve problems, and they present difficulties on factors such as prediction and transfer, capacity of synthesis and analysis, mainly. It was observed that the test requires the addition of a glossary in the present complex issues words, in order that it can be used again.
\end{abstract}

Keywords: Science education, solving problems, ability, tests. 


\section{Introdução}

$\mathrm{U}$

m dos objetivos da alfabetização científica ou do ensino de ciências em geral, é preparar os estudantes para resolverem problemas com os quais possam se deparar na vida cotidiana. Para que o ensino de ciências atinja esse objetivo, é importante reconhecer quais habilidades são importantes para que um indivíduo seja competente na solução de problemas. Nesse sentido, para que os professores da Educação Básica possam descrever as habilidades e também as dificuldades que os estudantes possuem, é importante estudar instrumentos que permitam descrever a capacidade de resolução de problemas.

Considerando o exposto, o presente trabalho está estruturado a partir da seguinte questão: "Quais os instrumentos disponíveis para descrever a capacidade de solucionar problemas? A revisão de literatura traz justificativas para a importância do ensino da resolução de problemas, bem como de instrumentos existentes para avaliar essa competência.

Na sequência, são descritos os resultados obtidos através da aplicação de teste específico para avaliar tal competência, realizado para verificar a adequação do mesmo.

\section{O ensino de ciências e a solução de problemas}

A fim possibilitar a construção de uma imagem real da ciência, de acordo com
Pozo \& Crespo (2009), as novas metas para a educação científica são a aprendizagem de conceitos e a construção de modelos; o desenvolvimento de habilidades cognitivas e de raciocínio científico; o desenvolvimento de habilidades experimentais e de resolução de problemas bem como $\mathrm{O}$ desenvolvimento de atitudes e valores, De acordo com Pozo \& Crespo (2009), a partir da concretização dessas metas, o ensino de ciências poderá viabilizar a formação de cidadãos atuantes e participativos da vida em sociedade.

Dito de outra forma:

Todos necessitamos utilizar
informação científica para realizar
opções que se nos deparam a cada dia;
todos necessitamos ser capazes de
participar em discussões públicas sobre
assuntos importantes que se relacionam
com a ciência e com a tecnologia; e todos
merecemos compartilhar a emoção e
realização pessoal que pode produzir a
compreensão do mundo natural (
CACHAPUZ et al., 2011, p. 20).

E como conseguir que o ensino de ciências concretize esse ideal? Parece que uma das maneiras para formar um aluno mais crítico, participativo e atuante na sociedade seja a utilização de estratégias de ensino mais ativas e envolventes para os estudantes. Nesse sentido, pesquisadores apontam para a utilização da resolução de problemas como estratégia de ensino nas escolas. Bonito (2010) afirma que o aluno só poderá compreender a metodologia científica se o ensino se basear em processo de resolução de problemas. Para Vasconcelos et al. (2007), o ensino através 
da resolução de problemas permite a construção de conhecimento conceitual, além de possibilitar o desenvolvimento de competências que o cidadão utiliza para enfrentar problemas no cotidiano, tais como selecionar informações, prever resultados, planejar, formular hipóteses, entre outros. Da mesma forma, García García \& Rodriguez Renteria (2012) apontam que as metodologias de ensino baseadas na resolução de problemas contribuem para desenvolver formas de pensamento favoráveis à construção de novos conhecimentos (aprender a aprender), característica importante na atual sociedade da informação.

Convém lembrar que a resolução de problemas requer o uso de diversas habilidades, bem como a utilização de estratégias de enfrentamento dos problemas, baseadas na análise e interpretação das situações que se estabelecem a partir dos modelos conceituais e de procedimentos sistematizados, tal como ocorre na Ciência (POZO et al., 1998). Assim sendo, é importante caracterizar as diversas atividades necessárias para que seja possível enfrentar um problema. Uma vez conhecidas as características ou estratégias necessárias à resolução de problemas, é possível verificar as facilidades e/ou dificuldades dos estudantes em aplicar o conhecimento na solução de problemas e nas diversas situações que se apresentam em seu cotidiano.

\section{A formação científica e as avaliações externas}

As avaliações externas se fazem cada vez mais presentes na educação formal, como objetivo de descrever a realidade educacional e propor políticas que visem à melhoria da educação (GODINHO \& FARIAS, 2013). Dentre as avaliações em nível nacional, tem-se a Prova Brasil, o ENEM e as iniciativas de avaliação de alguns estados, como o Saresp em SP, por exemplo. Em nível internacional, tem-se o PISA, que avalia a proficiência dos estudantes em leitura, matemática e ciências em diversos países, inclusive no Brasil.

No Brasil, em 2014, ocorreu um estudo inédito para avaliar o nível de letramento científico da população adulta, o Indicador de Letramento Científico (ILC), inspirado em programas de avaliação como o PISA e Inaf (este é um indicador de alfabetismo funcional). A partir de entrevistas, o ILC busca avaliar a capacidade de pessoas adultas em usar conceitos e procedimentos tipicamente científicos para explicar fenômenos, bem como avaliar a compreensão da linguagem técnico-científica e a capacidade de resolver problemas em situações cotidianas (INSTITUTO ABRAMUNDO, 2014).

A partir dos itens avaliados no ILC, é possível situar o indivíduo em uma escala de proficiência, organizada em quatro níveis, que exigem maior domínio de habilidades, além de conhecimentos referentes a gêneros e tipos textuais e a conceitos científicos necessários à para compreensão das situações propostas pelo ILC (INSTITUTO ABRAMUNDO, 2014). Os referidos níveis são:

Nível 1 - Letramento nãocientífico: nesse nível, o indivíduo consegue localizar informações 
explícitas em textos simples (tabelas ou gráficos, textos curtos) que envolvam temas do cotidiano, sem a exigência de domínio de conhecimentos científicos.

Nível 2 - Letramento científico rudimentar: nesse caso, o indivíduo resolve problemas que envolvam a interpretação e a comparação de informações e conhecimentos científicos básicos, que podem estar apresentados em textos diversos (tabelas e gráficos com mais de duas variáveis, imagens, rótulos), e que envolvam temáticas presentes no cotidiano.

Nível 3 - Letramento científico básico: o indivíduo elabora propostas de resolução de problemas com maior complexidade a partir de evidências científicas que estejam apresentadas em textos técnicos e/ou científicos (manuais, esquemas, infográficos, conjunto de tabelas), estabelecendo relações intertextuais em diferentes contextos.

Nível 4 - Letramento científico proficiente: o indivíduo é capaz de avaliar propostas e afirmações que exijam o domínio de conceitos e termos científicos em situações que envolvam contextos diversos (cotidianos ou científicos). Consegue elaborar argumentos sobre a confiabilidade ou veracidade de hipóteses formuladas e demonstra domínio do uso de unidades de medida (INSTITUTO ABRAMUNDO, 2014).

Apesar do ILC descrever grupos de letramento científico conforme as capacidades dos indivíduos, esta avaliação não é específica e detalhada o suficiente para determinar quais as dificuldades ou que habilidades necessitam ser mais desenvolvidas nos indivíduos, a fim de que os mesmos consigam resolver situações de uma forma mais eficiente e estratégica. Nesse sentido, García García \& Renteria Rodriguez (2012) elaboraram e validaram um teste para verificar a capacidade de resolver problemas, organizado em torno de sete processos característicos que, segundo os autores, são essenciais na resolução de problemas. Em ordem crescente de importância, esses fatores são:

1. Predição e transferência: indicam que transferir é utilizar os conhecimentos adquiridos em outros contextos, seja para realização de outras atividades ou para solucionar problemas. A transferência se faz evidente quando o indivíduo revisa padrões de solução que já conhece para solucionar problemas. Da mesma forma, prever o comportamento (elaborar hipóteses) dos fenômenos em estudo, em diversas condições, é importante para a resolução de problemas. Existem três indicadores que permitem a avaliação desse fator: a capacidade de selecionar a hipótese mais adequada, a capacidade de discernir a situação na qual a solução do problema é semelhante e aplicável, e a capacidade para identificar a melhor solução para um problema.

2. Capacidade de síntese: permite estabelecer relações entre as partes da situação apresentada, representar e descrever a situação levantada através de gráficos, ilustrações ou equações, a fim de emitir julgamentos ou conclusões. 
Pode ser avaliada através da capacidade de selecionar palavraschave, organizar elementos de algum texto e de representar formalmente o enunciado de um problema.

3. Leitura crítica de um enunciado: a boa compreensão de leitura ajuda os estudantes a estabelecerem relações e inferências sobre a informação necessária para a resolução do problema. Os dois indicadores deste fator são a capacidade de determinar inconsistências e a capacidade distinguir informações relevantes para a solução de problemas.

4. Análise: fator importante, pois na resolução de problemas se faz necessário separar informações importantes das irrelevantes, definir quais são as variáveis do problema e também quais as relações entre essas variáveis, bem como estabelecer aspectos conhecidos e desconhecidos para determinação das incógnitas. Para avaliar este fator, são levados em conta a capacidade de estabelecer relações e a capacidade de decompor um problema em problemas menores.

5. Interpretação da informação: para resolver um problema, a interpretação se faz necessária, pois permite estabelecer relações entre a análise dos dados e a hipótese elaborada, a fim de dar explicações a padrões ou tendências encontradas e emitir conclusões. A capacidade de interpretação de informações explícitas e implícitas é utilizada para avaliar este fator.

6. Compreensão metacognitiva de enunciados e processos: fator importante, pois permite estabelecer relações entre as variáveis do problema e emitir juízos sobre a maneira como estas se relacionam. Inclui três indicadores: selecionar rotas de solução, elaborar previsões e decidir que dados devem ser buscados para a resolução do problema.

7. Delimitação do problema: este fator permite identificar as questões que devem ser abordadas, quais os aspectos importantes para a sua solução bem como aqueles aspectos que não interferem na solução. É importante para que se estabeleçam as condições ou parâmetros que devem ser considerados para a resolução do problema e pode ser avaliado através da capacidade de delimitar e precisar as condições do problema.

Cada um dos fatores citados é avaliado mediante testes de múltipla escolha que necessitam a mobilização de cada um dos 16 indicadores. Apesar do mesmo ter sido criado para ser aplicado com estudantes colombianos, tal teste se mostra interessante para ser utilizado com adolescentes brasileiros. Primeiro, porque possibilita conhecer as habilidades e também as dificuldades específicas dos estudantes em resolver problemas. Segundo, por tratar-se de um teste de múltipla escolha, permitindo ao professor/aplicador o acesso rápido aos 
resultados, característica que o diferencia das avaliações externas, cujos resultados demoram a chegar ao professor. Além disso, a partir da descrição detalhada de cada fator considerado importante para resolver problemas, é possível elaborar outras questões. Dessa forma, este instrumento de avaliação se mostra importante para a utilização por professores, pois constitui um instrumento capaz de descrever a capacidade dos estudantes na solução de problemas, e a partir destes, organizar a prática pedagógica a fim de alcançar os objetivos do ensino de ciências.

\section{Metodologia}

O presente trabalho busca verificar a adequação de um teste para medir a capacidade de resolver problemas, elaborado por García García \& Renteria Rodriguez (2012) para estudantes brasileiros. Esse teste preconiza a utilização de sete características ou habilidades gerais para abordar e resolver um problema.

$\mathrm{O}$ teste anteriormente citado foi adaptado e organizado para adequar-se ao nível dos estudantes ao qual seria aplicado. Acrescentou-se questões do PISA, capazes de avaliar as mesmas habilidades propostas no teste e adequadas à faixa etária dos participantes, uma vez que o teste original descreve os indicadores que facilitam a solução de problemas. A fim de analisar a adequação do teste para verificar a capacidade de solucionar problemas, realizou-se um teste piloto, com estudantes do $8^{\circ}$ e $9^{\circ}$ ano de uma escola pública do município de IbirubáRS.
O teste descrito acima apresenta uma categorização de acordo com o número de acertos, conforme tabela 1. Salienta-se que o mesmo não foi utilizado com o objetivo de classificar os estudantes, mas sim, para descrever a capacidade de resolver problemas.

Tabela 1: Categorização da capacidade de resolver problemas de acordo com o número de acertos.

\begin{tabular}{l|c}
\hline CATEGORIA & PONTUAÇÃO \\
\hline Excelente & 13 a 16 \\
\hline Muito bom & 10 a 12 \\
\hline Bom & 7 a 9 \\
\hline Deficiente & 4 a 6 \\
\hline Insuficiente & 0 a 3 \\
\hline
\end{tabular}

Apresentamos a seguir as constatações referentes à aplicabilidade do teste, bem como uma visão sobre a capacidade de resolver problemas dos participantes.

\section{Resultados e discussão}

Participaram do teste-piloto, 26 estudantes, do $8^{\circ}$ e do $9^{\circ}$ ano do Ensino Fundamental de uma escola estadual no município de Ibirubá - RS, com idades entre 14 e 16 anos. Nessa amostra, há alunos com histórico de repetência, no ano atual de escolaridade ou de anos anteriores.

A fim de conhecer o nível sócioeconômico dos estudantes, o questionário apresentou uma questão que pedia o número de banheiros presentes na residência dos estudantes, pois conforme Tolentino Neto (2008), dessa forma é possível conhecer melhor o nível sócio-econômico das famílias brasileiras. $\mathrm{O}$ município conta com IDH 
0,765

(ATLAS

$\mathrm{DO}$

DESENVOLVIMENTO HUMANO NO BRASIL, 2013). A economia do município está baseada na atividade agrícola e industrial.

Dados do INEP mostram que a pontuação da escola na edição de 2013 da Prova Brasil foram 265,68 pontos em Língua Portuguesa e 268,43 em Matemática, nos quais os estudantes avaliados ficaram nos níveis de proficiência 3 e 4 . Nesta avaliação a escola foi classificada no grau 5 do nível sócio econômico (INEP, 2014). Na caracterização realizada com o teste, verificou-se que as residências dos estudantes têm entre um e três banheiros e que o nível de escolaridade dos pais desses estudantes, em sua maioria é de Ensino Fundamental incompleto. O teste, que consta de 16 questões de múltipla escolha, organizado em torno de pequenos textos, foi resolvido em cerca de 30 minutos. A figura 1 demonstra $\mathrm{O}$ desempenho dos estudantes no teste.

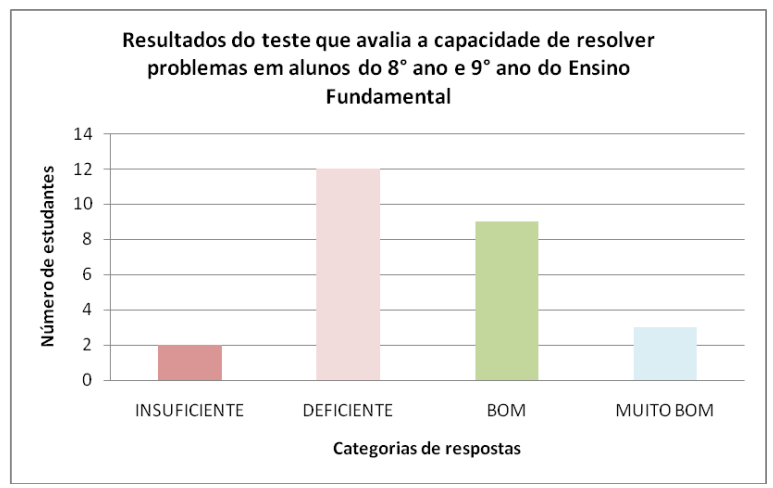

Figura 1: A capacidade de resolver problemas em alunos do $8^{\circ}$ e $9^{\circ}$ ano do Ensino Fundamental da EEEF Ibirubá.

Verificou-se que a maior parte dos estudantes que realizou o teste encontra-se nos níveis mais baixos de capacidade de resolução de problemas e que nenhum alcançou o nível Excelente.
A média de acertos ficou em 7,37 , sendo que 3 e 12 foram, respectivamente, os números mínimo e máximo de acertos. Dois alunos obtiveram 3 acertos e somente um atingiu 12 acertos.

Nas outras avaliações que testam os conhecimentos científicos, tais como o PISA, têm-se resultados similares. Os resultados obtidos na aplicação dessa prova em 2006, quando foram avaliados conhecimentos específicos das ciências, apontam que $27,8 \%$ dos alunos estão no nível 0 , ou seja, tais resultados não evidenciam que esses alunos possuam as competências científicas mínimas para a realização das tarefas mais simples propostas nas provas do PISA, Os resultados obtidos também não fornecem evidências de que os participantes apresentam habilidades para a solução de problemas em situações corriqueiras e familiares. É importante salientar que o nível 0 não existe na escala de proficiência do PISA, mas foi acrescentada no relatório brasileiro.

O nível 1 ficou constituído por 34,1\% da população, evidenciando que esta porcentagem de participantes apresenta um padrão de conhecimento científico tão limitado que tais alunos só conseguem aplica-lo em poucas situações familiares. Além disso, limitam-se a explicações científicas óbvias que se seguem, quase imediatamente, a uma evidência apresentada.

O nível 2 ficou constituído por 23,4\%, o nível 3 com 10,9\%, o nível 4 com $3,3 \%$, o nível 5 com $0,4 \%$ e nenhum aluno no nível 6. Ou seja, praticamente $60 \%$ dos alunos brasileiros avaliados no PISA não apresentam ou não têm 
noções mínimas de ciências (WAISELFISZ, 2009).

Da mesma forma, os resultados do ILC-2014

(INSTITUTO ABRAMUNDO, 2014), que avaliou adultos jovens (entre 15 e 40 anos), com o mínimo de cinco anos de escolaridade do ensino fundamental, mostraram que $16 \%$ da população avaliada encontra-se no nível 1 de proficiência científica; $48 \%$ da amostra estão no nível 2; 31\% no nível 3 e apenas 5\% no nível 4 . Ou seja, mais da metade da amostra avaliada não domina os conhecimentos e habilidades necessárias para resolver problemas ou para interpretar informações de natureza científica.

É preciso considerar que as dificuldades relacionadas como enfoque dos problemas e as estratégias de resolução são mais complexas para serem entendidas ou explicadas. As dificuldades não estão localizadas apenas no modelo mental elaborado pelo aluno, ou no grau de correspondência estabelecido para os dados, ou ainda, se o problema tem ou não significado; mas sim, nas restrições que derivam da escolha do problema e do enunciado apresentado (SIGÜENZA MOLINA, 2000 apud SILVÉRIO \& MAESTRELLI, 2013). Considerando que, desenvolver a capacidade de organização lógica do pensamento e construir uma consciência crítica do mundo que cerca o indivíduo são condições necessárias para a alfabetização científica (SASSERON \& CARVALHO, 2011), os resultados mostram que as habilidades para esse fazer científico ainda estão distantes do esperado.
O ensino de ciências deve "contribuir para a compreensão de conhecimentos, procedimentos e valores que permitam aos estudantes tomar decisões e perceber tanto as muitas utilidades da ciência e suas aplicações na melhora da qualidade de vida, quanto as limitações e consequências negativas de seu desenvolvimento" (CHASSOT, 2003, p.99). Dessa forma, a partir dos resultados apresentados pelos estudantes participantes desse estudo, tem-se a percepção de que a forma como se dá o ensino de Ciências, na atualidade, ainda está longe de promover, de fato a alfabetização científica.

A Tabela 2 indica a frequência de acertos dos estudantes em cada questão ou indicador avaliado. A análise desses resultados indica em quais questões tiveram maior dificuldade de resolução. É possível considerar que tal resultado indica as dificuldades que os estudantes apresentam e dessa forma, aponta as habilidades que devem receber maior atenção durante o planejamento e as aulas de ciências, e também, durante a elaboração do material didático utilizado para essas etapas da escolaridade.

As questões 3, 7, 8, 11 e 14, que correspondem a $31,2 \%$ do questionário, tiveram um índice de acertos superior a $50 \%$. As demais questões tiveram baixo percentual de acertos. Tal resultado pode indicar dificuldades apresentadas pelos estudantes e, dessa forma, permite uma pré-avaliação de quais habilidades poderiam ser mais desenvolvidas em sala de aula. Por outro lado, torna-se importante analisar 
e refletir sobre as questões com baixo possíveis motivos desses resultados. índice de acertos para verificar os

Tabela 2 - Número de acertos por questão/indicador avaliado no teste.

\begin{tabular}{|c|c|c|c|c|}
\hline FATOR & $\begin{array}{c}\% \\
\text { ACERTOS } \\
\text { POR } \\
\text { FATOR }\end{array}$ & INDICADORES & $\begin{array}{l}\text { TOTAL DE } \\
\text { ACERTOS } \\
\quad(n=26)\end{array}$ & $\%$ \\
\hline \multirow[t]{3}{*}{$\begin{array}{l}\text { Predição e } \\
\text { transferência }\end{array}$} & \multirow[t]{3}{*}{$46,1 \%$} & $\begin{array}{l}\text { 1) Seleção da hipótese mais } \\
\text { adequada }\end{array}$ & 12 & 46,15 \\
\hline & & $\begin{array}{l}\text { 2) Seleção a situação com } \\
\text { solução semelhante ao } \\
\text { problema dado }\end{array}$ & 8 & 30,77 \\
\hline & & $\begin{array}{l}\text { 3) Identificação a melhor } \\
\text { solução para o problema }\end{array}$ & 16 & 61,54 \\
\hline \multirow{3}{*}{$\begin{array}{l}\text { Capacidade de } \\
\text { síntese }\end{array}$} & \multirow[t]{3}{*}{$29,4 \%$} & 4) Seleção de palavras-chave & 6 & 23,08 \\
\hline & & $\begin{array}{l}\text { 5) Organização de elementos } \\
\text { do texto }\end{array}$ & 8 & 30,77 \\
\hline & & $\begin{array}{l}\text { 6) Representação formal de } \\
\text { um problema }\end{array}$ & 9 & 34,62 \\
\hline \multirow{2}{*}{$\begin{array}{l}\text { Capacidade de } \\
\text { leitura crítica } \\
\text { de um } \\
\text { enunciado }\end{array}$} & \multirow[t]{2}{*}{$57,6 \%$} & $\begin{array}{lll}\text { 7) } & \begin{array}{l}\text { Identificação } \\
\text { inconsistências }\end{array} & \text { de } \\
\end{array}$ & 14 & 53,85 \\
\hline & & $\begin{array}{l}\text { 8) } \begin{array}{l}\text { Seleção de informação } \\
\text { relevante }\end{array} \\
\end{array}$ & 16 & 61,54 \\
\hline \multirow[t]{2}{*}{$\begin{array}{l}\text { A capacidade } \\
\text { de análise }\end{array}$} & \multirow[t]{2}{*}{$40,3 \%$} & $\begin{array}{ll}\text { 9) } & \begin{array}{l}\text { Estabelecimento de } \\
\text { relações }\end{array} \\
\end{array}$ & 11 & 42,31 \\
\hline & & $\begin{array}{l}\text { 10) Divisão do problema em } \\
\text { subproblemas }\end{array}$ & 10 & 38,46 \\
\hline \multirow[t]{2}{*}{$\begin{array}{l}\text { Capacidade de } \\
\text { interpretação } \\
\text { da informação }\end{array}$} & \multirow[t]{2}{*}{$44,2 \%$} & $\begin{array}{lr}\text { 11) Interpretação } & \text { de } \\
\text { informação } & \text { explícita: } \\
\text { dedução a partir de dados }\end{array}$ & 14 & 53,85 \\
\hline & & $\begin{array}{l}\text { 12) Interpretação de } \\
\text { informação explícita: } \\
\text { elaborar conclusões } \\
\end{array}$ & 9 & 34,62 \\
\hline \multirow{3}{*}{$\begin{array}{l}\text { Capacidade de } \\
\text { compreensão } \\
\text { metacognitiva } \\
\text { de enunciados } \\
\text { e processos }\end{array}$} & \multirow[t]{3}{*}{$41,02 \%$} & $\begin{array}{l}\text { 13) Identificação de sequências } \\
\text { implícitas: selecionar rotas } \\
\text { de solução }\end{array}$ & 10 & 38,46 \\
\hline & & $\begin{array}{l}\text { 14) Inferência explícita de } \\
\text { predições: } \\
\text { predições/hipóteses }\end{array}$ & 14 & 53,85 \\
\hline & & $\begin{array}{l}\text { 15) Inferência de informação } \\
\text { implícita: buscar dados } \\
\text { necessários }\end{array}$ & 8 & 30,77 \\
\hline $\begin{array}{l}\text { 7. Capacidade de } \\
\text { delimitação do } \\
\text { problema }\end{array}$ & $30,7 \%$ & $\begin{array}{l}\text { 16) Delimitação e precisão das } \\
\text { condições do problema }\end{array}$ & 8 & 30,77 \\
\hline
\end{tabular}

Cada questão avalia alguma problemas e a partir da análise das habilidade importante na resolução de questões têm-se uma descrição sobre as 
principais dificuldades dos alunos. Considerando o total de acertos para cada um dos sete fatores, percebeu-se que os estudantes apresentaram dificuldade na maior parte deles, sendo que apenas o fator 3 (Capacidade de leitura crítica de um enunciado) resultou em maior percentual de acertos (57,3\%). Dessa forma, a partir da utilização do teste também é possível propor atividades para auxiliar os estudantes a superarem essas dificuldades.

Em relação ao fator 1 (Predição e transferência), que segundo García García \& Renteria Rodriguez (2012) é o fator mais importante no processo de resolução de problemas, caracterizouse, como o indicador mais crítico, a capacidade de selecionar a situação com solução semelhante ao problema dado (Figura 2). Esse ponto merece atenção, uma vez que para resolver problemas, normalmente, o indivíduo busca situações semelhantes em seus esquemas de conhecimento, antes de mobilizar ideias ou formas de solução (POZO et al., 1998). Dessa forma, se o indivíduo não consegue selecionar problemas que tenham soluções semelhantes, como poderá chegar à solução do problema? Ou seja, os resultados obtidos neste estudo demonstram que estudantes não estão preparados para reconhecer padrões ou estabelecer comparações que permitam aos mesmos verificar a existência ou não de similaridades entre situações ou informações. Por outro lado, em que momentos das aulas de ciências, são ofertadas atividades que incentivem os estudantes a observar e localizar padrões?

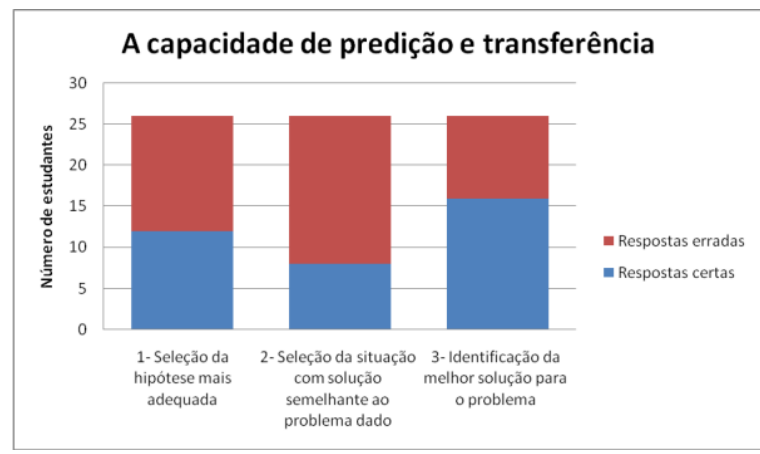

Figura 2: Resultados das questões referentes ao fator 1 do teste utilizado para avaliar o desempenho na resolução de problemas ( $\mathrm{n}=$ 26).

A questão que avaliou esta capacidade é transcrita a seguir:

Para chegar a tempo em seu trabalho, Pedro viaja de metrô, que sai às 7 horas da estação A. Em um dia, Pedro chegou às 7 h1min na estação, quando o trem já havia partido. Levando em conta que o trem viaja a $50 \mathrm{~km} / \mathrm{h}$, que a estação seguinte está a $2 \mathrm{~km}$ de distância e que o metrô realiza paradas de 5 minutos em cada estação, Pedro decidiu caminhar até à estação seguinte, a uma velocidade de $4 \mathrm{~km} / \mathrm{h}$ para ver se alcançava o metrô. Será que Pedro conseguirá alcançar o trem na estação seguinte? Qual dos problemas a seguir se resolveria de maneira semelhante?

a. Calcular em que momento os atletas $\mathrm{A}$ e $\mathrm{B}$ se encontrariam, correndo com a mesma velocidade, mas em sentidos contrários

b. Calcular o tempo que o atleta A gastaria para alcançar o atleta $\mathrm{B}$, se o atleta $B$ estivesse à frente do atleta $\mathrm{A}$, porém numa velocidade menor.

c. Calcular o tempo que os atletas A e B levariam para chegar ao final, se partissem do mesmo ponto, 
porém com velocidades diferentes.

d. Calcular que velocidade o atleta $B$ deveria atingir para alcançar o atleta $\mathrm{A}$, se o atleta $\mathrm{A}$ estivesse à frente do atleta B e parasse para descansar.

Dos alunos participantes, nove marcaram a alternativa $C$, que, no entanto, não apresenta uma situação semelhante àquela descrita no enunciado do problema. Possíveis dificuldades para resolver a questão podem estar na extensão do enunciado, que apresenta informações numéricas de diferentes grandezas, sendo necessário, ainda, compará-las entre si.

Dentre todos os fatores avaliados, pode-se considerar que os alunos participantes apresentaram maior dificuldade na capacidade de síntese, pois em nenhuma das questões referentes aos indicadores desse fator houve mais da metade de acertos. (Figura 3). Em relação à seleção de palavras-chave, a maior parte dos estudantes não conseguiu selecionar, dentre as alternativas, aquela que representasse as palavras adequadas para realizar uma busca. A questão que avaliou este indicador foi:

Várias palavras foram sublinhadas na afirmação a seguir.

Astrônomos prevêem que, visto de $\underline{\text { Netuno }}$ haverá um trânsito de Saturno diante do Sol no decorrer deste século.

Entre as palavras sublinhadas, quais seriam as três mais úteis para se fazer uma busca na internet ou em uma biblioteca, a fim de se descobrir quando esse trânsito ocorreria?
a. Astrônomos, Netuno, Saturno
b. Sol, Netuno, Saturno

c. Saturno, Netuno, trânsito

d. Astrônomo, trânsito, Saturno

A alternativa mais escolhida entre os estudantes foi a alternativa D, quando a alternativa correta seria a C. Possíveis dificuldades da questão podem ter decorrido da própria interpretação do enunciado, bem como da falta de uma visão global da situação que possibilitasse perceber quais as palavras que realmente seriam úteis para uma pesquisa. É um fato estranho, uma vez que as buscas na Internet, em geral, são realizadas por palavras-chave.

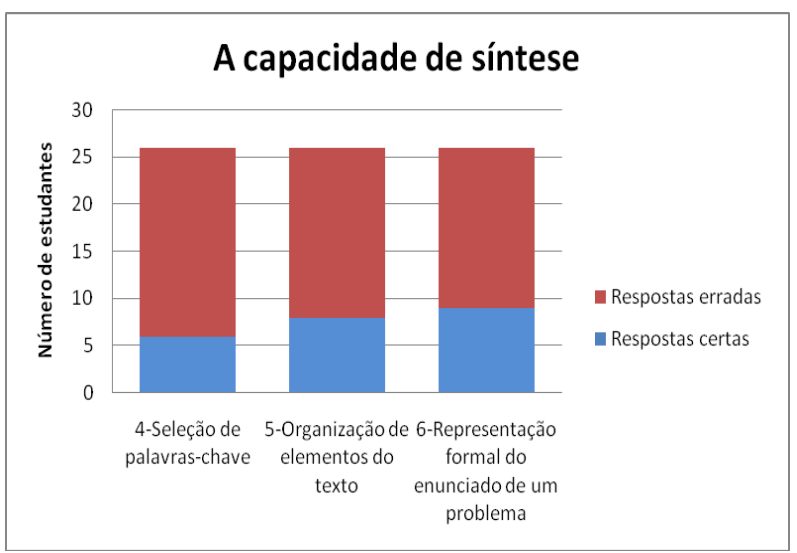

Figura 3: Resultados das questões referentes ao fator 2 do teste para avaliar o desempenho na resolução de problemas $(n=26)$.

Apesar de as respostas relativas à capacidade de leitura crítica de um enunciado (Fator 3 - figura 4) resultarem em mais acertos do que nas questões referentes aos outros fatores, não é possível afirmar que os estudantes apresentaram facilidade nesse fator, uma vez que o percentual de acertos nesse fator foi de 57,6\%.

De acordo com Santos (2007), o ensino de ciências limitou-se a um processo de memorização de vocábulos, de sistemas de classificação e de fórmulas, no qual os estudantes aprendem os termos científicos, mas 
não são capazes de extrair o significado dessa linguagem. Se considerarmos a leitura como a construção de significados a partir da interação com diversos tipos textuais (SOUZA, 2010) e a compreensão como habilidade básica para a ativação de outras atividades mentais importantes na resolução de problemas, podemos inferir que essa dificuldade de leitura acaba por prejudicar os outros fatores/indicadores. Considerando que os estudantes avaliados apresentaram dificuldades para identificar inconsistências, conforme indica a figura 4, percebe-se que os mesmos apresentam um nível de leitura superficial. Os resultados da Prova Brasil (INEP, 2013) mostram que, em relação à Língua Portuguesa, a maior parte dos estudantes da escola onde foi efetuada a coleta de dados, encontra-se nos níveis 3 e 4 da escala de proficiência, nos quais o estudante localiza informações explícitas nos textos lidos.

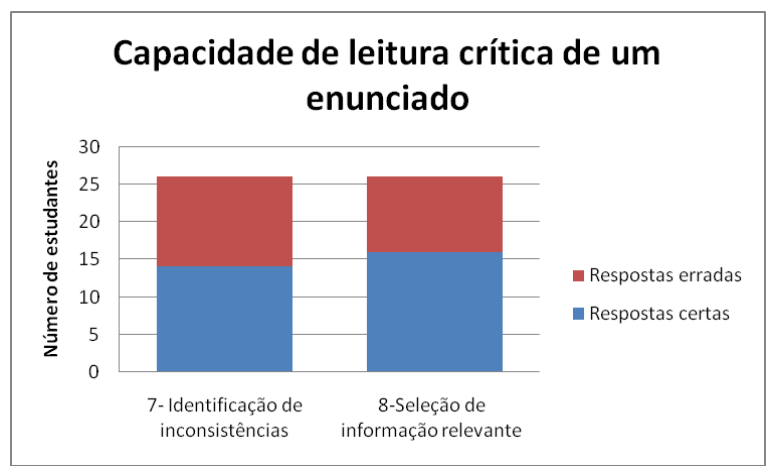

Figura 4: Resultados das questões referentes aos fator 3 do teste para avaliar o desempenho na resolução de problemas $(n=26)$.

Sobre a capacidade de análise (Fator 4), percebeu-se que os estudantes apresentam dificuldade em estabelecer relações entre as variáveis ou dados/informações do problema e também em imaginar um problema na forma de problemas menores, conforme demonstra a figura 5 .

Segundo Silvério \& Maestrelli (2013), o professor deve auxiliar o aluno a habituar-se a adotar suas próprias concepções no processo de resolução de problemas, além de oportunizar a reflexão sobre os dados e a construção de autonomia e crítica na tomada de decisões. Em relação a esse item, cabe discutir sobre a função do material didático. Que tipos de atividades os mesmos propõem? Visam o desenvolvimento das habilidades requeridas para solucionar problemas ou apenas a cópia literal de definições e conceitos?

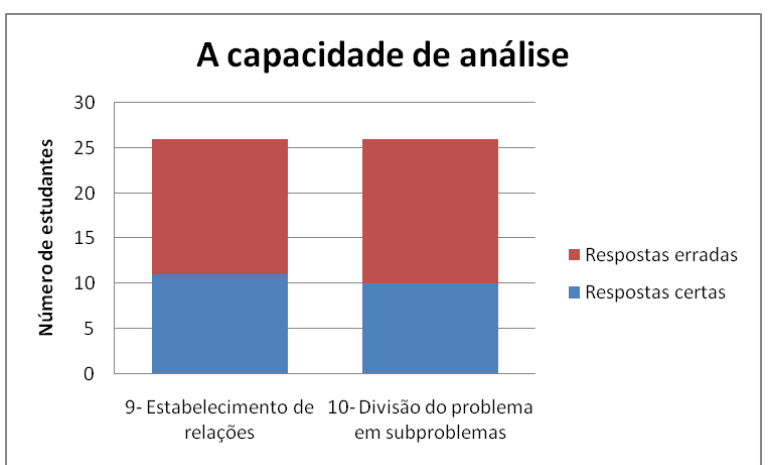

Figura 5: Resultados das questões referentes aos fator 4 do teste para avaliar o desempenho na resolução de problemas $(n=26)$.

O quinto fator considerado relevante por García García e Renteria Rodriguez (2012), na resolução de problemas, apresenta semelhanças com o nível 2 do ILC, pois ambos consideram a habilidade de interpretação. No testepiloto, percebeu-se que os estudantes participantes apresentaram maior dificuldade no indicador 12 (Figura 6), que se refere à interpretação da informação explícita para elaborar conclusões. Isso é preocupante, uma vez que a cada dia temos acesso a inúmeras informações ou mesmo propagandas 
que induzem ao consumo de produtos ou serviços. Estas, muitas vezes, utilizam-se de argumentos que poderiam facilmente ser percebidos como irreais ou enganosos, se as pessoas analisassem essas informações.

A mesma interpretação ou análise exposta acima vale para situações que exigem a tomada de decisão individual ou a participação da sociedade em decisões coletivas, tais como a implantação de usinas hidrelétricas (a exemplo das hidrelétricas em estudo de implantação ao longo do rio Uruguai) ou mesmo em questões atuais, como a escassez de recursos hídricos, consumo e produção de energia. Essas e outras questões do cotidiano, sobre as quais a mídia veicula informações, precisam ser reelaboradas pelos indivíduos a fim de que possam ter opinião própria $\mathrm{e}$ também atitudes coerentes. No entanto, “o ensino escolar de ciências, de maneira geral, vem sendo desenvolvido de forma totalmente descontextualizada, por meio da resolução ritualística de exercícios e problemas escolares que não requerem compreensão conceitual mais ampla" (SANTOS, 2007, p. 486). Tal forma de ensino não contribui para uma formação mais ampla e que torne os indivíduos aptos a compreenderem e utilizarem as informações.

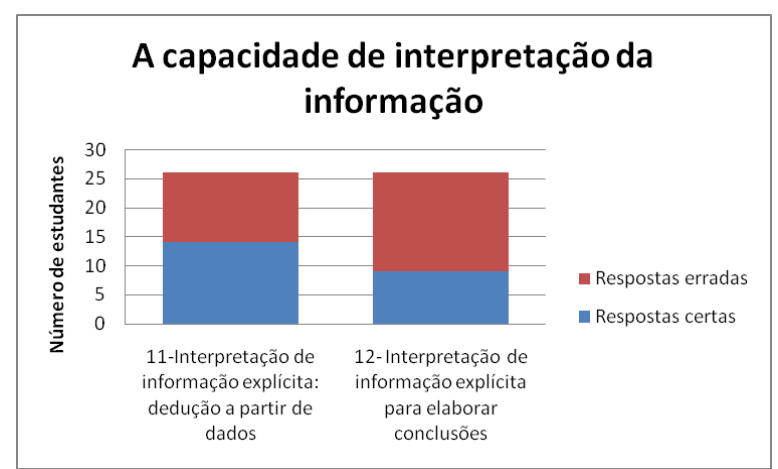

Figura 6: Resultados das questões referentes ao fator 5 do teste para avaliar o desempenho na resolução de problemas $(n=26)$.

Em relação ao fator 6, percebeu-se que os estudantes têm dificuldade na identificação de sequências implícitas para solucionar um problema e maior dificuldade para inferir quais dados devem ser buscados para resolver a situação (Figura 7). O mesmo acontece com o fator 7 , no qual se verifica a capacidade de delimitar uma situaçãoproblema a fim de solucioná-la (Figura 8).

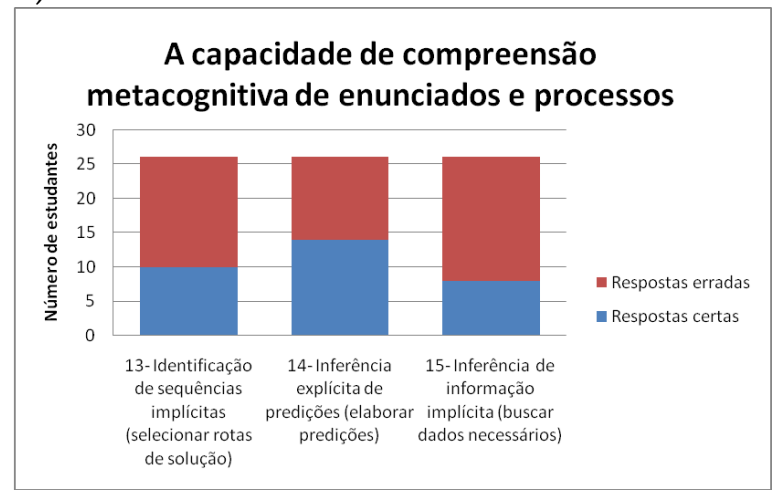

Figura 7: Resultados das questões referentes ao fator 6 do teste para avaliar o desempenho na resolução de problemas $(n=26)$.

Apesar de García García \& Renteria Rodriguez (2012) terem considerado esses fatores menos importantes na resolução de problemas, os dados obtidos apontam dificuldades dos estudantes em planejar estratégias de solução. De acordo com Pozo et al. (1998), é importante que os estudantes adquiram algumas atitudes no decorrer das aulas de ciências, como o questionamento e reflexão sobre fatos observados e a vivência de procedimentos úteis na solução de problemas, tais como conhecer estratégias de busca, sistematização e análise de dados. Esses conhecimentos são importantes tanto para aqueles que 
almejam seguir seus estudos nas áreas científicas quanto para que os indivíduos, em geral, possam compreender o mundo ao seu redor.

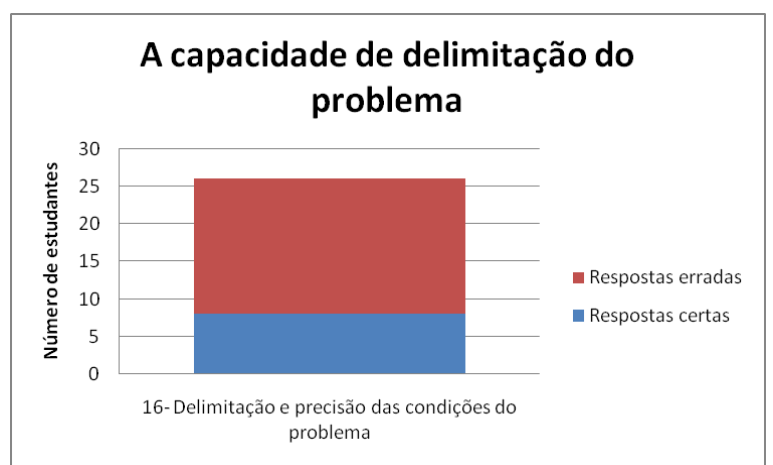

Figura 8: Resultados das questões referentes ao fator 7 do teste para avaliar o desempenho na resolução de problemas $(n=26)$.

Ao final do teste, os alunos foram questionados sobre suas impressões em relação ao mesmo. Indicaram que não compreenderam o que algumas questões solicitavam por não conhecerem o significado de algumas palavras. Tal dificuldade de compreensão pode ser explicada em parte, pela falta de uma leitura eficiente. Para Souza (2010, p. 30), “a leitura competente é essencial para um bom rendimento escolar [...]". Da mesma forma, a capacidade de leitura fluente também pode levar o estudante a atingir resultados melhores em testes ou avaliações externas, como o PISA, Prova Brasil e outros.

$\mathrm{Na}$ atualidade, as situações de ensino devem preparar os indivíduos para "aprender a agir na complexidade" (ZABALA, 2010, p.112). Ou seja, no cotidiano as situações ou problemas geralmente não se apresentam de forma simples, requerendo a ativação de habilidades e estratégias previamente conhecidas. Morin (2011) defende que o pensamento complexo, capaz de relacionar, contextualizar e ligar diferentes saberes é uma necessidade à educação do futuro. Pozo et al. (1998) reitera que a aprendizagem da solução de problemas propicia aos indivíduos uma autonomia cada vez maior na aplicação e escolha de estratégias para então transferí-los a outros contextos e situações. Dessa forma, considera-se que o ensino de Ciências que priorize uma abordagem a partir de problemas, deve desenvolver a utilização de habilidades e procedimentos necessários ao enfrentamento dos mesmos, o que requer o estudo de instrumentos que possam diagnosticar quais as dificuldades dos estudantes.

\section{Conclusões}

Foi possível constatar que entre os participantes do estudo piloto, a maior parte encontra-se nos níveis mais baixos da capacidade de resolver problemas. Os fatores nos quais os participantes apresentaram maior dificuldade foram os fatores Predição e transferência; Capacidade de síntese; Capacidade de Análise; Capacidade de compreensão metacognitiva de enunciados e processos; e Capacidade de delimitação do problema.

Apesar do exposto, faz-se necessário considerar que, talvez, os alunos participantes não tenham tido contato com atividades semelhantes durante as aulas, o que pode ter comprometido o pensamento utilizado na resolução das questões. Conforme afirmam Pozo et al. (1998), é importante propiciar aos estudantes momentos e atividades que demandem o uso de estratégias e habilidades de resolução de problemas, 
para que os mesmos possam aprendêlos.

Em relação às indicações relativas às palavras com significado desconhecido para os estudantes, conclui-se que o acréscimo de um glossário, apresentando o significado dessas palavras, será necessário.

A partir das adequações a serem realizadas, o teste será reaplicado com outras turmas de $8^{\circ}$ ano do ensino fundamental. Espera-se que a partir dessas adequações, o teste possa se consolidar como uma ferramenta capaz de reconhecer as dificuldades dos alunos, para que assim, o professor possa propor atividades adequadas à superação das mesmas.

Outra proposta refere-se à adaptação desse teste em questões abertas serem aplicadas com um grupo focal, a fim de verificar como os estudantes abordam e resolvem as questões. Nesse caso, será possível obter uma visão mais ampla e detalhada sobre a capacidade de resolver problemas e a validade do processo utilizado.

\section{Referências}

ATLAS DO DESENVOLVIMENTO HUMANO NO BRASIL. 2013. Disponível em <http://www.atlasbrasil.org.br/2013/pt Lperfil m/ibiruba rs\#idh> Acesso em 4 fev. 2015.

BONITO, J. Ensino das ciências de base cognitiva: perspectivas atuais. 2010. Disponível em: <http://hdl.handle.net/10174/4652>. Acesso em 20 jan. 2015.
CACHAPUZ, A. et al. (2011). A necessária renovação no ensino de ciências. 2 ed. São Paulo: Cortez, 2011.

CHASSOT, A. Alfabetização científica: uma possibilidade para a inclusão social. Revista Brasileira de Educação, 22 (1), 89-100, 2003.

GARCÍA GARCÍA, J. J.; RENTERIA RODRIGUEZ, E. La medición de la capacidad de resolucion de problemas em las ciências experimentales. Ciência \& Educação, 18 (4), 755-767, 2012.

GODINHO, J. D; FARIAS, M. E. Inserção de ciências visando a compatibilização do SAEB com o PISA e seus reflexos nas Políticas Educacionais. Atas do IX Encontro Nacional de Pesquisa em Educação em Ciências. 2013. Disponível em < www.nutes.ufrj.br/abrapec/ixenpec/at as/resumos/R1524-1.pdf $>$. Acesso em 30 nov. 2014.

INEP. Boletim de desempenho Prova Brasil. 2014. Disponível em $<$ http://sistemasprovabrasil.inep.gov.b r/provaBrasilResultados/view/boletim Desempenho/boletimDesempenho.sea m> Acesso em: 10 fev. 2014.

INSTITUTO ABRAMUNDO. Indicador De Letramento Científico: Relatório Técnico da edição 2014. São Paulo, 2014.

MORIN, E. Os sete saberes necessários à educação do futuro. São Paulo: Cortez, 2011.

POZO, J. I.; ECHEVERRÍA, M. P.P.; CASTIllO, J. D.; ANGÓN, Y. P. A solução de problemas: aprender a resolver, resolver para aprender. Porto Alegre: Artes Médicas, 1998. 
POZO, J. I.; CRESPO, M. A. G. A aprendizagem e o ensino de ciências: do conhecimento cotidiano ao conhecimento científico. Porto Alegre: Artes Médicas, 5.ed., 2009.

SANTOS, W. L. P. Educação científica na perspectiva de letramento como prática social: funções, princípios e desafios. Revista Brasileira de Educação, 12(36), 474-550, 2007. Disponível em <http://www.scielo.br/pdf/rbedu/v12n 36/a07v1236.pdf>. Acesso em 30 nov. 2014.

SASSERON, L. H.; CARVALHO, A. M. P. Alfabetização científica: uma revisão bibliográfica. Investigações em ensino de ciências, 16(1), 59-77, 2011.

SILVÉRIO, L. E. R.; MAESTRELLI, S. R. P. Ensinar genética resolvendo problemas: potencial de uma estratégia didática. Em: Docência em Ciências e Biologia: propostas para um continuado (re) iniciar/ Org. Leandro Duso, Marilisa Bialvo Hoffmann. Ijuí: Ed. Unijuí, 2013, 320p.

SINGÜENZA MOLINA, A. F. Formación de modelos mentales em la genética. Enseñanza de las Ciencias, 18(3), 439-450, 2000.

SOUZA, L. S. Compreensão leitora nas aulas de ciências. 217 f. Tese (Doutorado - Programa de Pós Graduação em Educação. Área de Concentração: Ensino de Ciências e Matemática) - Faculdade de Educação da Universidade de São Paulo, São Paulo, 2010.

TOLENTINO NETO, L. C. B. Os interesses e posturas de jovens alunos frente às ciências: resultados do Projeto ROSE aplicados no Brasil. 170 f. Tese (Doutorado - Programa de Pós Graduação em Educação. Área de Concentração: Ensino de Ciências e Matemática) - Faculdade de Educação da Universidade de São Paulo, São Paulo, 2008.

VASCONCELOS, C.; B. LOPES, N. COSTA, L. MARQUES E S. CARRASQUINHO. Estado da arte na resolução de problemas em Educação em Ciências. Revista Electrónica de Enseñanza de las Ciencias. 6 (2), 235245, 2007.

WAISELFISZ, J. J. O Ensino das Ciências no Brasil e o PISA. São Paulo: Editora Sangari, 2009.

ZABALA, A. Como aprender e ensinar competências. Porto Alegre: Artes Médicas, 2010. 